\title{
Affect expression and self-regulation capacities of infants exposed in utero to psychotropics
}

\author{
Pratibha N. Reebye ${ }^{1}{ }^{*}$, Tammy W. C. $\mathbf{N g}^{2}$, Shaila Misri ${ }^{3}$ and Irena Stikarovska ${ }^{1}$ \\ 1 Infant Psychiatry Clinic, Department of Psychiatry, University of British Columbia, Vancouver, BC, Canada \\ 2 University College Hospital, London, UK \\ ${ }^{3}$ Reproductive Psychiatry Clinic, Department of Psychiatry, University of British Columbia, Vancouver, BC, Canada
}

\section{Edited by:}

Anne Glowinski, Washington

University School of Medicine, USA

Reviewed by:

Natalie Weder, New York University, USA

Cynthia Rogers, Washington

University School of Medicine, USA

*Correspondence:

Pratibha N. Reebye, Infant Psychiatry Clinic, Department of Psychiatry,

British Columbia's Children's Hospital, 4500 Oak Street, Vancouver, BC,

Canada V6H $3 \mathrm{~N} 1$.

e-mail:preebye@cw.bc.ca
This study explored the affect expression and self-regulation capacities of 8-month-old infants exposed in utero to psychotropic medications. This was a continuation of our previous study conducted on the same cohort when the infants were 3 months old. Psychotropics implicated included selective serotonin reuptake inhibitors (SSRIs), and a benzodiazepine derivative anxiolytic (clonazepam). The three comparison groups were: control ( $n=23$; infants not exposed to psychotropics in utero), SSRI-alone ( $n=22$; infants exposed to SSRIs only and having mothers who had a primary diagnosis of depressive disorder without having comorbid anxiety disorder), and SSRI+ group ( $n=15$; infants gestationally exposed to SSRIs and clonazepam and having mothers that had both clinical depression and anxiety disorder). Using the Parent-Child Early Relational Assessment Scale, infants were assessed in a dyadic context during free play and a structured task. There were significant differences in psychotropic exposed and non-exposed dyads regarding infant negative affect management. There were significant associations between the SSRI+ group of mothers and infant negative affect. This group of mothers also showed significant associations with infants' averting and avoiding behaviors in both play situations. The SSRI-alone group was similar to the control group and showed variable associations with infant's positive, negative, and sober moods unlike the SSRI+ group. There were no differences in infants' capacity for self-regulation in psychotropic exposed and non-exposed groups. Increased awareness of these vulnerable subgroups (SSRI-alone and SSRI+) is needed, in order to safeguard these dyads through better support systems and improved management.

Keywords: infants, psychotropics, gestational exposure, self-regulation, affect expression

\section{INTRODUCTION}

Affect expression and self-regulation are important skills that are fundamental for optimal infant socio-emotional development. These faculties can be compromised by prenatal stress and aberrant postnatal experiences. Infants' affective experiences and selfregulatory capacities can be affected in utero directly or indirectly by a multitude of stressors ranging from maternal depression and/or anxiety to direct placental transfer of psychotropics.

Although depression affects people of all ages, race, and sex; women during their childbearing years are at the highest risk of developing depression that is associated with psychiatric disorders such as anxiety disorders and substance-related disorders (Le Strat et al., 2011). Unfortunately, not all depressed/anxious pregnant women access timely treatment for their symptoms (Marcus, 2009). The burden of untreated maternal depression and anxiety is borne by both mothers and their fetuses/infants (Maughan et al., 2007; Marcus, 2009; Bernier et al., 2010).

The effects of antenatal anxiety/depression examined in longitudinal designs are mixed. Newborns of prenatally depressed mother showed less responsiveness to stimuli in several studies (Field, 2011). Weinberg et al. (2008) evaluated the effects of maternal depression and panic disorder, and found that infants belonging to these two groups showed similar "still face behavior" as infants from non-clinical samples. One study that focused on pregnancy-specific anxiety during mid-pregnancy predicted lower mental and motor developmental scores at 8 months (Buitelaar et al., 2003). The Avon Longitudinal Study (O'Connor et al., 2002) found that antenatal maternal anxiety was associated with behavioral and emotional problems in 4-year-old children. In this same cohort, prenatal depression was associated with delayed development in 18-month-old infants (Deave et al., 2008). Van den Bergh and Marcoen (2004) found no significant associations between maternal anxiety and internalizing behaviors in 8- and 9-year-old children as reported by their parents and caregivers. However, high antenatal maternal anxiety was related to attention deficit hyperactivity disorder symptoms and externalizing problems in 8 - and 9-year-olds in this same study.

Some researchers reported that whilst maternal depression is a risk factor, it does not affect attachment patterns in children when maternal depression is resolved in early childhood (Campbell et al., 2004). It has also been found that infant interaction behaviors improved when interacting with a non-depressed teacher or 
father (Field, 1998). This suggests timely support for the depressed mother is an important step toward improved child developmental adaptation.

Evidence is accumulating, albeit mostly from animal studies, that self-regulation processes can be disturbed prenatally. The offspring of prenatally stressed non-human primates demonstrated more problems with attention and coping with novel situations (Schneider, 1992; Clarke and Schneider, 1997). Huizink and Buitelaar (2000) suggested that stress in humans cannot be compared to animals in experimental research, where the routine form of stressor is usually externally inflicted on the animal. However, Oberlander et al. (2008) found that maternal depression, specifically third trimester exposure to maternal depression/anxiety, affects potential epigenetic regulation of glucocorticoid receptor gene expression.

Of particular importance to this study is the question of depressed mothers with comorbid diagnoses such as anxiety disorder. These complicated clinical situations often require therapeutic approaches that include combinations of psychotropic medications. A study by Carter et al. (2001) found that the effects of maternal depression were accounted for by mothers with comorbid diagnoses, who had less optimal interactions, and infants with higher rates of insecurity than either mothers with depression only or mothers with no psychopathology.

Treating depressed/anxious pregnant mothers who seek help can also be complicated. Pharmacotherapy still occupies the gold standard for treatment of maternal depression. However, use of medications during pregnancy is controversial. Some authors cautioned against publication bias with regards to negative studies on this topic (Koren and Nickel, 2011). Nevertheless, this discussion has become more relevant as use of antidepressants such as selective serotonin reuptake inhibitors (SSRIs) is rising. In a population-based cohort study in Netherlands, the exposure rate to SSRIs increased from 12.2 to 28.5 pregnancies per 1000 in 8 years (Bakker et al., 2008). Safety concerns are continually being expressed regarding the use of SSRIs, serotonin-norepinephrine reuptake inhibitors (SNRIs), antiepileptic drugs, mood stabilizers, benzodiazepines, and antipsychotics during pregnancy (Way, 2007; Gentile and Bellantuono, 2009; Sackett et al., 2009; Tuccori et al., 2009; Gentile, 2010).

In this study, the psychotropic medications that were investigated included SSRIs, and a benzodiazepine derivative anxiolytic (clonazepam). Therefore, further discussion will focus on these two psychotropic agents. Use of benzodiazepines (BZD) in pregnancy is laden with associations with neonatal withdrawal syndromes, facial clefts, and cardiac malformations (Cohen et al., 1989; McElhatton, 1994). Research has yielded conflicting information regarding the use of SSRIs during pregnancy and its deleterious effects on the developing fetus. Several authors (Oberlander et al., 2004; Sackett et al., 2009; Tuccori et al., 2009) noted significant associations between gestational exposure to SSRIs and pulmonary hypertension of the newborn and transient adaptation syndrome. Associations between SSRI exposure and earlier deliveries and lower Apgar scores, have also been described. Oberlander et al. (2004) demonstrated transient neonatal symptoms such as mild respiratory distress and to a lesser degree hypotonia following prenatal psychotropic exposure; the results were inconclusive regarding direct causality with SSRI exposure. Our previous findings concurred with Oberlander's in that the addition of clonazepam altered paroxetine absorption, thereby increasing medication levels, and transient neonatal symptoms (Misri et al., 2004). Recently, longer gestational exposure to SSRIs was shown to be related to lower birth weight, respiratory distress, and reduced gestational age (Oberlander et al., 2008). Similarly, Casper et al. (2011) reported that the length of in utero exposure to SSRIs negatively affects neonatal adjustment. Although it was shown that SSRIs do not increase the rate of major congenital malformations in neonates (Pastuszak et al., 1993; Goldstein et al., 1997; Misri et al., 2000; Einarson et al., 2001; Simon et al., 2002), subtle disturbances were detected.

Studies on neurocognitive development of infants that were exposed to SSRI or tricyclic antidepressants yield mixed results (Nulman et al., 1997; Gentile, 2005). Casper et al. (2003) found that SSRIs administered during fetal development may have subthe effects on motor development. Mulder et al. (2011) noted high motor activity of SSRI-exposed fetuses. However, a review by Udechuku et al. (2010) did not find significant differences on developmental outcomes between in utero SSRI-exposed and non-exposed children.

Infant self-regulatory capacities in the context of in utero exposure to psychotropics are not extensively reported. However, parent-child relationships are uniformly identified as playing an important part in developing child's self-regulatory capacity (Schore, 1994; Bernier et al., 2010).

Finally, it is crucial to understand what exactly is implied for the developing fetus when exposed to psychotropics. Neurotransmitters and neuromodulators are important for the building of neural circuitry. This function can be disturbed, with long-term behavioral effects, by prenatal or neonatal stress and drugs that cross placenta (Herlenius and Lagercrantz, 2001). Serotonin plays a role in regulating physiological functions such as sleep, appetite, and temperature. It is believed that serotonin activity is present at birth and continues throughout adulthood. Cortical serotonin receptors develop in an ontogenetic fashion in the cerebral cortex during the postnatal period (Aitken and Tork, 1988). SSRIs increase serotonin availability in the synaptic clefts and due to placental transfer; there is the possibility of increased serotonin levels in neonates prenatally exposed to SSRIs. However, it is not known whether this early exposure potentiates further synaptic growth or up-regulation. Specific benzodiazepine binding also occurs as early as 7 weeks post conception and clonazepam has this ability to bind, pointing toward early ontogeny of the central benzodiazepine receptors (Hebebrand et al., 1988).

The current study focused on infants exposed to SSRIs and a benzodiazepine where the key neurotransmitters involved are serotonin and GABA. This study was a continuation of a preceding study looking at affect expression in prenatally psychotropic (SSRI and clonazepam) exposed infants. The previous study was conducted on the same group of infants aged 3 months. It was shown that mothers with comorbid diagnoses of depression and anxiety were more reactive in their emotional expressions to the affect expression of their infants than were control or depressed mothers (Reebye et al., 2002). 
In this phase of the investigation, affect expression and selfregulation capacities of infants at 8 months of age were assessed to find out if in utero exposure to psychotropic medications has primed these infants for behavioral teratogenicity. Many mothers stop nursing their infants after 3-6 months for practical reasons such as returning to work. Discontinuation of breast-feeding at 12 weeks has already been identified as a risk for the return of maternal depressive factors (Taveras et al., 2003). Study dyads were expected to settle into a routine past this vulnerable period to allow precise measurement of affect expression and self-regulation. Therefore, 8 months seemed a suitable cut off point for the investigation of this cohort. This time period also facilitated observation of complex social interactions between mothers and infants (Stern, 1995). As infants take greater part in social interactions, their emotional regulation capacity increases (Posner and Rothbart, 2002). Moreover, this 6- to 10 -month stage of mother-infant relationship has not yet been extensively explored, with some exceptions (Davids et al., 1963; Buitelaar et al., 2003). This study focused on this critical window, specifically on the capacities of affect expression and self-regulation in the gestationally SSRI-alone/SSRI+ exposed and non-exposed infants.

The a priori hypothesis was that of three groups (controls, SSRIalone, and SSRI+), the infants of control mothers would be more successful with self-regulation than infants of mothers using psychotropics in pregnancy as assessed on the Parent-Child Early Relational Assessment (PCERA) and measures of self-regulation. In psychotropic exposed dyads, it was expected that the SSRI+ group, where infants had mothers with comorbid diagnoses that were receiving SSRIs and an anxiolytic, would experience more difficulty with self-regulation than the infants whose mothers were taking only SSRIs and did not have comorbid anxiety. Furthermore, it was predicted that infants of control mothers would be able to express affect appropriately to the demands of the situation (free play and structured play) than infants that were gestationally exposed to psychotropics.

Infants' postnatal affective experiences are a combination of their individual developmentally determined contribution and that derived from maternal affect. The outcome measures chosen for this study reflect a combination of strategies to tap on infants' affective style and the mutual regulation processes in the mother-infant context.

\section{MATERIALS AND METHODS}

The study was undertaken with the approval from the University of British Columbia Research Ethics Board and the Children's and Women's Health Centre of British Columbia Research Ethics Committee.

\section{RECRUITMENT AND SAMPLE CHARACTERISTICS}

Subjects for the SSRI-alone and SSRI+ groups were recruited during pregnancy. Subjects for the non-exposed control group were recruited from day 1 postpartum. Recruitment of SSRI-alone and SSRI+ groups was carried out over 2 years from the outpatient referrals to the Reproductive Mental Health Program at St. Paul's Hospital and British Columbia's Women's Hospital in Vancouver. Eligible subjects were medically healthy women who received one or more Axis I diagnoses during pregnancy. Women were excluded from participating if they were abusing substances, psychotic, suicidal, or exposed to known teratogens.

Subjects in this study were not serially approached. They were invited from the cohort involved in our previous 3 months postpartum study. The attrition rate was very low with the withdrawal of only one subject and one subject-changing category from the original SSRI-alone to SSRI+ group.

Of the 60 final participant dyads, 22 of the infants had been exposed to SSRIs only and their mothers had a primary diagnosis of depressive disorder without having comorbid anxiety disorder; these dyads made up the SSRI-alone group. Eleven of these mothers were taking paroxetine (Paxil), seven were taking fluoxetine (Prozac), and four were taking sertraline (Zoloft). A further 15 participant mothers were taking SSRIs and clonazepam (Rivotril) of which, 13 were taking paroxetine and clonazepam and 2 were taking fluoxetine and clonazepam. These 15 mothers had both clinical depression and anxiety disorder and with their infants made up the SSRI+ group. The SSRI-alone and SSRI+ group women all remained on medication up until the end of the study.

All subjects in the experimental group (SSRI-alone and SSRI+) were given a mental status examination by a reproductive psychiatrist. The clinician also scored Hamilton Anxiety Rating Scale (HAM-A; Hamilton, 1959), Hamilton Depression Rating Scale (HAM-D; Hamilton, 1960), and Clinical Global Impression Scale (CGI; Guy, 1976). Out of 37 participants in the psychotropic exposed group, all the mothers suffered from clinical depression according to the Diagnostic and Statistical Manual of Mental Disorders, Fourth edition (DSM-IV) criteria. The comorbid diagnoses consisted of panic disorder, generalized anxiety disorder, and obsessive-compulsive disorder. At the time of recruitment, there were no mothers with the diagnosis of bipolar disorder.

A control group of non-depressed (clinically and by selfdisclosure), non-treated (psychotropic medications) healthy (no other serious comorbid pathology) mothers and their healthy infants (living with biological mothers) were recruited after delivery from pediatricians' clinics. Initially, 128 dyads were approached for the control group. Ninety-four of those dyads refused, were not suitable or were difficult to contact. Thirty-four dyads were suitable; out of which we have complete data on 23 motherinfant dyads. The research coordinator approached mothers from this list of normal healthy pregnancies and deliveries during the first or second day postpartum. A screening chart review of the antenatal birth record was performed by the research coordinator prior to approaching the mother to confirm the presence or absence of any treatment for depression. Exclusionary criteria included a documentation of depression or treatment for depression. No self-report questionnaires were used initially but a psychiatrist who was blind to study procedures provided clinical assessment of control mothers at 2 and 8 months postpartum. HAM-D questionnaire was only scored at 2 months in this group.

Inclusion of infants of depressed/anxious mothers who were not treated pharmacologically would have assisted our ability to separate the effects of maternal mood from those of prenatal medications exposure. However, we were unable to recruit such a group due to the nature of the referral patterns to the 
Reproductive Mental Health Program and due to Ethics Board requirements. It should also be noted, that such a sample would be self-selected, which could have introduced further biases (e.g., severity of anxiety/depressive symptoms) into the study.

This sample is representative of the population served by the catchment area of Children's and Women's Health Center of British Columbia.

\section{PROCEDURES}

In our 3-month study (Reebye et al., 2002), mother and infant were videotaped during free play and feeding task. In this study, mother and infant were videotaped when the infant was 8 months of age at the Biobehavioural Research Laboratory. It was decided that structured play task would be used rather than feeding, due to the variable feeding times of each infant.

The PCERA (Clark, 1985) was used to rate the affective and behavioral quality of the parent-infant relationship during two sequences: free play (where the mother was instructed to play with her infant as she would at home) and structured play task (a novel task where the infant was to find hidden cubes.) Free play and structured play task sequence lasting a total of $10 \mathrm{~min}$ were analyzed.

Infants were assessed on the Bayley Scales of Infant Development at age 8 months (Bayley, 1993). A reproductive psychiatrist interviewed mothers in the psychotropic exposed group and scored the CGI (Guy, 1976), the HAM-D (Hamilton, 1960), and the HAM-A (Hamilton, 1959). The reproductive psychiatrist also clinically assessed control mothers.

\section{Maternal measures}

The HAM-D (Hamilton, 1960) is used to assess the severity of depression. The 21-item version was used. Items are scored from
0 to 4 , the higher the score, the more severe the depression. A cut off point of 7 indicates a clinical level of depression.

The HAM-A (Hamilton, 1959) consists of 14 items. This scale measures the severity of symptoms of anxiety, tension, palpitations, breathing difficulties, sleep disturbances, restlessness, and other physical symptoms. The items are scored from 0 to 4 , with a progression from none (score 0 ) to severe (score 4 ). The accepted clinical cut off point is a total score of 14 .

The CGI (Guy, 1976) is used to measure the global impression of the patient and has a single item measured on a 7-point scale from 1 (normal, not ill) to 7 (extremely ill).

\section{Affect expression measures (using PCERA)}

Positive infant affect variable was constructed with expressed positive infant affect, happy mood. Negative infant affect composite variable included expressed negative affect, and irritable mood.

Positive maternal affect variable was constructed with expressed positive affect, enjoyment, and pleasure. Maternal negativity composite variable included expression of negative affect, displeasure, and contingent response to negative behavior.

Maternal sensitivity during play interaction is a logical indicator of healthy parent-child relationships (Welch et al., 2003) and was therefore an appropriate measure to record for this study. As measured through PCERA, three components were scored: reads cues and responds sensitively, quality of verbalization, and contingent response to positive behavior.

\section{Self-regulation measures (using PCERA)}

For this study, self-regulation variables consisted of attentional, behavioral, social, emotional, and mutual regulation (Eisenberg et al., 2000; Calkins and Fox, 2002). Table 1 explains the regrouping of variables as used in our analysis.

Table 1 | Self-regulation variables.

\begin{tabular}{|c|c|c|c|}
\hline & Infant variables & Dyadic variables & Maternal variables \\
\hline Attentional & $\begin{array}{l}\text { Attentional abilities } \\
\text { Persistence }\end{array}$ & Joint attention/activity & - \\
\hline Behavioral & $\begin{array}{l}\text { Alertness/interest } \\
\text { Passivity/lethargy } \\
\text { Hyperactivity }\end{array}$ & - & - \\
\hline Social & $\begin{array}{l}\text { Social behavior of child - initiates } \\
\text { Social behavior of child - responds } \\
\text { Avoiding/averting/resistance }\end{array}$ & - & $\begin{array}{l}\text { Quality and amount of physical contact-positive } \\
\text { Quality and amount of physical contact-negative } \\
\text { Quality and amount of visual contact with child } \\
\text { Structures and mediates environment }\end{array}$ \\
\hline Emotional & $\begin{array}{l}\text { Positive infant affect } \\
\text { Negative infant affect } \\
\text { Happy mood } \\
\text { Emotional lability }\end{array}$ & - & $\begin{array}{l}\text { Expressed parental affect-positive } \\
\text { Expressed parental affect-negative }\end{array}$ \\
\hline Mutual regulation & Self-regulation & $\begin{array}{l}\text { Anger/hostility } \\
\text { Flat/empty/constricted } \\
\text { Tension/anxiety } \\
\text { Enthusiasm/joyfulness } \\
\text { Joint attention/activity } \\
\text { Reciprocity } \\
\text { Organization/regulation of interactions } \\
\text { State similarity }\end{array}$ & $\begin{array}{l}\text { Contingent responsivity to child's positive behavior } \\
\text { Contingent responsivity to child's negative behavior }\end{array}$ \\
\hline
\end{tabular}




\section{Infant and dyadic measures}

The PCERA scoring system examines up to 65 parent, child, and dyadic variables. Each item of the PCERA is rated on a 5-point Likert scale that offers a comprehensive description of the interaction between parent and child, with scores of 1 and 2 indicating areas of concern, 3 as some concern, and 4 and 5 as areas of strength. As a result, variables measuring negative behavior (i.e., maternal variables of expressed negative affect, displeasure, and contingent response to negative behavior; infant variables of expressed negative affect, irritable mood, apathetic/withdrawn, and sober; and dyadic variables of flat/constricted and tension/anxiety) were effectively reverse coded. For example, while a mother showing a great deal of appropriate positive affect would receive an expressed positive affect score of 5 , indicating an area of strength. A mother showing a great deal of negative affect would receive a score of 1 on the expressed negative affect scale, indicating an area of weakness. High scores on PCERA variables should thus always be interpreted as positively valenced, indicating better functioning.

\section{CODING PROCEDURES}

Two research assistants were trained on five sequences (feeding, diapering, free play, structured task, and separation-reunion sequence) of maternal-infant interaction items on PCERA. The training included approximately $30 \mathrm{~h}$ of reviewing tapes and coding with the investigator who had established inter-rater reliability with the author of PCERA. The two research assistants who were blind to the study rated all the tapes.

A sample of 10 tapes (20\% of entire sample) were randomly selected and rated by a trained coder who was also blind to infant and maternal background characteristics. Inter-rater reliability was established during the entire coding procedure, taking samples at the beginning and over regular intervals until the final coding was done on a total of $20 \%$ of the sample. (Two coders carried one out of every five codings). This reliability was maintained to $85 \%$ on feeding, structured task, and free play segments. Random reliability checks were made on the scores obtained through different segments on PCERA scoring system.

Table 2 | Affect expression and self-regulation composite variables: Cronbach's alpha coefficients during structured play and free play.

\begin{tabular}{llll}
\hline Composite variable & $\begin{array}{l}\text { Range of } \\
\text { variable }\end{array}$ & $\begin{array}{l}\text { Structured } \\
\text { play }\end{array}$ & $\begin{array}{l}\text { Free } \\
\text { play }\end{array}$ \\
\hline AFFECT EXPRESSION & & & \\
\hline Positive maternal affect & $3-15$ & 0.87 & 0.82 \\
Maternal sensitivity & $2-10$ & 0.78 & 0.84 \\
Maternal negativity & $3-15$ & 0.72 & 0.78 \\
Positive infant affect & $2-10$ & 0.81 & 0.79 \\
Negative infant affect & $2-10$ & 0.81 & 0.79 \\
SELF-REGULATION & & & \\
Social behavior of child & $2-10$ & 0.72 & 0.61 \\
Positive infant affect & $2-10$ & 0.78 & 0.93 \\
Affective quality of interaction & $4-20$ & 0.79 & 0.62 \\
Mutuality & $4-20$ & 0.80 & 0.87
\end{tabular}

\section{CONSTRUCTION OF DATA SETS AND STATISTICAL ANALYSIS Data reduction}

Composite variables were computed due to the high intercorrelations between some maternal variables and some infant variables. This allowed fewer variables and logical clustering of certain rating scales. Cronbach's alpha (a measure of internal consistency based on the average inter-item correlation) was calculated for each composite variable and is shown in Table 2 . Three of the resulting composites; maternal sensitivity, positive infant affect, and negative infant affect, thus have ranges from 2 to 10, while positive maternal affect and maternal negativity have ranges from 3 to 15 . Affective qualify of interaction and mutuality variables have ranges from 4 to 20 .

\section{Missing data}

Unfortunately, there was incomplete maternal psychiatric data. Some subjects were missing data for three variables; the HAMA, HAM-D, and the CGI. The decision was taken to omit these subjects when comparing maternal mood against the mutual regulation variables. This left 16 mothers in the SSRI-alone group and 11 mothers in the SSRI+ group at 8 months.

\section{Statistical analysis}

Mean values and standard deviations were calculated for every composed maternal, infant, and dyadic variable and for each of the three groups (control, SSRI-alone, and SSRI+) for both structured play and free play interaction sequences between mother and infant. To determine significant differences among groups, ANOVA were conducted for each variable and sequence. To determine the direction and strength of the relationship between variables within each group, Kendall's tau b correlation coefficients were calculated. Kendall's tau b is a measure of association between two variables that is designed to be used with ordinal data such as that produced by the PCERA and similar qualitative rating measures. Correlations between the three groups were determined: (a) non-exposed control, (b) SSRI-alone, and (c) SSRI+.

\section{RESULTS}

\section{MATERNAL DEMOGRAPHICS (Table 3)}

There were no significant differences between the three study groups apart from years of education; mothers in the control group had significantly more years of education than the two psychotropic exposed groups $[F(2,56)=4.28, p=0.02]$.

\section{INFANT CHARACTERISTICS (Table 4)}

All infants were born at full term with normal birth weights and lengths. However, there were significant differences between the mean infant head circumferences of the three groups $[F(2,57)=3.24, p \leq 0.05]$.

\section{GROUP DIFFERENCES FOR AFFECT EXPRESSION AND DYADIC VARIABLES}

The group mean values and standard deviations for the control, SSRI-alone, and SSRI+ groups were compared and only one variable showed group differences: anger/hostility in the free play situation, and group mean values were minimally discrepant even on this variable. 
Table 3 | Maternal background demographic characteristics.

\begin{tabular}{|c|c|c|c|}
\hline & $\begin{array}{l}\text { Control } \\
(n=23)\end{array}$ & $\begin{array}{l}\text { SSRI-alone } \\
(n=22)\end{array}$ & $\begin{array}{l}\text { SSRI+ } \\
(n=15)\end{array}$ \\
\hline \multicolumn{4}{|l|}{ Marital status } \\
\hline Married & $22(96 \%)$ & $21(95 \%)$ & $14(93 \%)$ \\
\hline Single & - & $1(5 \%)$ & $1(7 \%)$ \\
\hline Divorced/separated & $1(4 \%)$ & - & - \\
\hline Maternal age $\left(\right.$ year) ${ }^{a}$ & $32(4.5)$ & $31(4.0)$ & $31(4.7)$ \\
\hline \multicolumn{4}{|l|}{ Ethnicity } \\
\hline White & $19(83 \%)$ & 19 (86\%) & $14(93 \%)$ \\
\hline Indian/Asian & $3(13 \%)$ & $2(9 \%)$ & - \\
\hline Native Indian & - & $1(5 \%)$ & - \\
\hline Other & $1(4 \%)$ & - & $1(7 \%)$ \\
\hline Maternal education (year) ${ }^{a}$ & $16.2(2.8)^{*}$ & $14.5(3.0)$ & $13.6(2.3)$ \\
\hline \multicolumn{4}{|l|}{ Past employment } \\
\hline Homemaker & - & $3(14 \%)$ & $3(20 \%)$ \\
\hline Professional & $17(74 \%)$ & $14(63 \%)$ & $6(40 \%)$ \\
\hline Technical & $2(9 \%)$ & $2(9 \%)$ & - \\
\hline Other & $4(17 \%)$ & $3(14 \%)$ & $6(40 \%)$ \\
\hline \multicolumn{4}{|l|}{ Medication during pregnancy ${ }^{b}$} \\
\hline No. of days on SSRI & $\mathrm{n} / \mathrm{a}$ & $189.5(32-293)$ & $162(56-275)$ \\
\hline No. of days on clonazepam & $\mathrm{n} / \mathrm{a}$ & $\mathrm{n} / \mathrm{a}$ & 110 (44-208) \\
\hline \multicolumn{4}{|l|}{ Severity of symptoms at entry ${ }^{a}$} \\
\hline HAM-A & - & $13.37(8.66)^{\mathrm{c}}$ & $19.13(13.97)$ \\
\hline HAM-D & - & $17.84(6.87)^{\mathrm{c}}$ & $17.93(9.68)$ \\
\hline \multicolumn{4}{|c|}{ Severity of symptoms at 2 months $^{a}$} \\
\hline HAM-A & - & $11.89(11.66)^{\mathrm{c}}$ & $12.10(10.74)^{d}$ \\
\hline HAM-D & $3.52(3.37)$ & $9.11(8.63)^{\mathrm{c}}$ & $10.50(10.36)^{d}$ \\
\hline \multicolumn{4}{|c|}{ Severity of symptoms at 8 months ${ }^{a}$} \\
\hline HAM-A & - & $5.75(7.10)^{\mathrm{e}}$ & $15.27(12.77)^{f}$ \\
\hline HAM-D & - & $3.44(6.91)^{\mathrm{e}}$ & $11.55(6.49)^{f}$ \\
\hline
\end{tabular}

${ }^{a}$ Mean (standard deviation), ${ }^{b}$ median (range), ${ }^{c} n=19,{ }^{d} n=10,{ }^{e} n=16,{ }^{f} n=11$, ${ }^{*} p=0.02$.

Table 4 | Infant characteristics.

\begin{tabular}{llll}
\hline & $\begin{array}{l}\text { Control } \\
(\boldsymbol{n = 2 3})\end{array}$ & $\begin{array}{l}\text { SSRI-alone } \\
(\boldsymbol{n}=\mathbf{2 2})\end{array}$ & $\begin{array}{l}\text { SSRI+ } \\
(\boldsymbol{n}=\mathbf{1 5})\end{array}$ \\
\hline Sex & $10 \mathrm{M}, 13 \mathrm{~F}$ & $13 \mathrm{M}, 9 \mathrm{~F}$ & $7 \mathrm{M}, 8 \mathrm{~F}$ \\
${\text { Birth weight }(\mathrm{g})^{\mathrm{a}}}^{\text {Gestational age (week) }}$ & $3406(439)$ & $3381(415)$ & $3481(422)$ \\
Length at birth (cm) & $39.3(1.3)$ & $39.6(1.3)$ & $39.3(1.1)$ \\
Head circumference at birth (cm) & $34.9(1.7)^{*}$ & $33.8(1.3)^{*}$ & $34.5(1.0)^{*}$ \\
BAYLEY SCALES AT 8 MONTHS & & & \\
Mental Development Index & $99(5.5)$ & $100(6.1)$ & $97(4.5)$ \\
Psychomotor Development Index & $97(8.6)$ & $91(9.5)$ & $93(8.6)$
\end{tabular}

${ }^{a}$ Mean (standard deviation), ${ }^{*} p<0.05$

\section{MATERNAL-INFANT AFFECT CORRELATIONS IN THE CONTROL, SSRI,} AND SSRI+ GROUPS (Table 5)

In free play, we found that mothers who belonged to the control and SSRI-alone groups showed that their positive affect and maternal sensitivity correlated to positive infant affect. However, this pattern changed for SSRI-alone dyads when faced with external demands and structured situation as compared to control group dyads.

Infant sober mood as described by PCERA includes frowns, wrinkling of the forehead, or looks of consternation. When the infants were sober, we found that during free play, the SSRI-alone group of mothers displayed a higher maternal sensitivity compared to control group mothers. In terms of structured play, however, control group mothers responded with significantly higher maternal sensitivity than mothers from experimental (SSRI-alone and SSRI+) groups.

The SSRI+ group showed a markedly different pattern from either the control or the SSRI-alone groups. Positive infant affect and sober mood had no significant correlations with any of the maternal variables in the SSRI+ group. However, strong and significant correlations were found between infant negative affect and all three maternal variables in both free play and structures task situations.

\section{SELF-REGULATION COMPONENTS AND MUTUAL REGULATION}

There were no significant differences among the three groups in the variables grouped under attentional, behavioral, social, emotional, or mutual regulation parameters.

\section{MUTUAL REGULATION VARIABLES AND RELATIONSHIP WITH MATERNAL MOOD (Table 6)}

There were no significant negative associations between mutual regulation variables and maternal mood as measured by HAM-A and HAM-D in both play situations in the three groups. Positive associations were found in the SSRI-alone group between maternal anxiety and self-regulation in the structured play, and between maternal anxiety and affective quality of interaction in the free play. As reported in Table 6, SSRI-alone group mothers had subclinical anxiety symptoms at 8 months. No significant correlations were found between mutual regulation infant affect component variables and HAM-A and HAM-D scores. CGI results are not reported in the Table as they were insignificant and the information obtained through HAM-D and HAM-A scores deemed sufficient.

\section{MOTHER-CHILD SOCIAL INTERACTION VARIABLES FOR THE THREE GROUPS (Table 7)}

For control group dyads, there were significant correlations between both the social behavior of the child composite and the child's avoiding, averting, and resistance behavior with the mother's amount and quality of negative physical contact, in structured play sequences. Mothers in the control group were thus more negative when their infants showed avoidance or resistance, however in response to children's social overtures they reacted less negatively. There were no significant associations in the free play task between the infant and maternal social variables in the control group.

In the SSRI-alone group, there were no relationships between the social behavior of the child composite or the child's avoiding, averting, and resistance behavior and the mother's amount and quality of negative physical contact. The associations in the free play situation could not be analyzed as the quality and amount of 
Table 5 | Intercorrelations (Kendall's tau b) between maternal variables and infant variables for the three groups during structured play and free play at 8 months.

\begin{tabular}{|c|c|c|c|c|c|c|c|c|c|}
\hline \multirow[t]{2}{*}{ Maternal variables } & \multicolumn{3}{|c|}{ Control } & \multicolumn{3}{|c|}{ SSRI-alone } & \multicolumn{3}{|c|}{ SSRI+ } \\
\hline & $\begin{array}{l}\text { Positive } \\
\text { infant } \\
\text { affect }\end{array}$ & $\begin{array}{l}\text { Negative } \\
\text { infant } \\
\text { affect }\end{array}$ & $\begin{array}{l}\text { Sober } \\
\text { mood }\end{array}$ & $\begin{array}{l}\text { Positive } \\
\text { infant } \\
\text { affect }\end{array}$ & $\begin{array}{l}\text { Negative } \\
\text { infant } \\
\text { affect }\end{array}$ & $\begin{array}{l}\text { Sober } \\
\text { mood }\end{array}$ & $\begin{array}{l}\text { Positive } \\
\text { infant } \\
\text { affect }\end{array}$ & $\begin{array}{l}\text { Negative } \\
\text { infant } \\
\text { affect }\end{array}$ & $\begin{array}{l}\text { Sober } \\
\text { mood }\end{array}$ \\
\hline \multicolumn{10}{|l|}{ STRUCTURED PLAY } \\
\hline Positive maternal affect & $0.38 *$ & 0.03 & $0.46^{*}$ & $0.34^{*}$ & $0.33^{*}$ & 0.26 & 0.32 & $0.48^{*}$ & -0.02 \\
\hline \multicolumn{10}{|l|}{ FREE PLAY } \\
\hline Positive maternal affect & $0.75^{* * *}$ & 0.14 & $0.51 * *$ & $0.49 * *$ & -0.16 & 0.32 & 0.41 & $0.68 * *$ & 0.37 \\
\hline Sensitivity & $0.76 * * *$ & 0.26 & $0.52^{* *}$ & $0.57^{* *}$ & 0.16 & $0.65 * * *$ & 0.21 & $0.57^{* *}$ & -0.06 \\
\hline Negativity & 0.31 & 0.22 & 0.20 & $0.66 * *$ & 0.03 & $0.51 * *$ & 0.28 & $0.80 * * *$ & 0.05 \\
\hline
\end{tabular}

${ }^{*} p \leq 0.05,{ }^{* *} p \leq 0.01,{ }^{* *} p \leq 0.001$

Table 6 | Kendall's tau b correlation coefficients between mutual regulation variables during both interaction sequences at 8 months and HAM-A and HAM-D indices at 8 months for SSRI-alone and SSRI+ groups and at $\mathbf{2}$ months for control group.

\begin{tabular}{|c|c|c|c|c|c|c|}
\hline Mutual regulation variables & \multicolumn{2}{|c|}{ Control } & \multicolumn{2}{|c|}{ SSRI-alone $(n=16)$} & \multicolumn{2}{|c|}{ SSRI+ (n= 11) } \\
\hline \multicolumn{7}{|l|}{ STRUCTURED PLAY } \\
\hline Contingent response to child behavior: positive & - & -0.121 & 0.187 & 0.211 & 0.229 & -0.092 \\
\hline Affect quality of interaction & - & -0.061 & 0.198 & 0.087 & -0.090 & -0.339 \\
\hline Mutuality & - & -0.328 & 0.109 & -0.015 & -0.226 & -0.090 \\
\hline \multicolumn{7}{|l|}{ FREE PLAY } \\
\hline Contingent response to child behavior: positive & - & -0.196 & 0.372 & 0.294 & -0.049 & 0.049 \\
\hline Contingent response to child behavior: negative & - & 0.139 & Constant & Constant & 0.259 & 0.065 \\
\hline
\end{tabular}

${ }^{*} \alpha=0.05$.

Table 7 | Intercorrelations (Kendall's tau b) between maternal social variables and infant social variables for the three groups during structured play and free play at 8 months.

\begin{tabular}{|c|c|c|c|c|c|c|}
\hline Maternal variables & \multicolumn{2}{|c|}{ Control } & \multicolumn{2}{|c|}{ SSRI-alone } & \multicolumn{2}{|c|}{ SSRI+ } \\
\hline \multicolumn{7}{|l|}{ STRUCTURED PLAY } \\
\hline Quality and amount of physical contact: negative & $0.52 * *$ & $0.55^{* *}$ & 0.09 & -0.07 & 0.37 & $0.61 * *$ \\
\hline
\end{tabular}

${ }^{*} p \leq 0.05,{ }^{* *} p \leq 0.01,{ }^{* *} p \leq 0.001,{ }^{5}$ constants.

Note: High scores indicate more functional behavior for all variables. 
negative physical contact in the free play situation was invariant in the SSRI-alone group.

The SSRI+ group showed a different pattern of interactions. In the structured play task, there was a positive association between avoidant, averting, and resistant behaviors and the maternal variable of quality and amount of negative physical contact, as in the control group. However, unlike the control group, mothers in the SSRI+ group also showed more negative physical contact when children showed initiation of and response to social overtures and when they were avoidant or resistance in the free play task.

\section{DISCUSSION}

\section{AFFECT EXPRESSION}

The first phase of analysis in this cohort (Reebye et al., 2002) indicated that the SSRI+ group (infants and mothers) showed different patterns of association between maternal and infant affect expression compared to the other two groups. At 8 months of age, differential patterns of association between maternal and infant affect occurred in all three groups, however, the control and the SSRI-alone (depression without comorbid anxiety disorder) groups exhibited more similarities than differences whereas the SSRI+ group (depression comorbid with anxiety disorder) showed a distinct pattern. The severity of mood symptoms (anxiety and depression) of the SSRI+ group was not negatively or significantly associated with any maternal and infant interactions variables, as showed in Table 6.

Parental management of infant negative affect is generally more challenging as compared to management of infant positive or sober affect. This may explain why significant differences between the three groups were found in this specific area, as showed in Table 5 . Control group mothers were able to cope with infant negative affect in both play situations. Positive correlation between maternal negativity and negative infant affect were found in psychotropic exposed groups. However, this correlation was significant in both play situations for SSRI+ group, compared to the SSRI-alone group who showed significant correlation in the structured play sequence only. Structured play placed specific demands on the dyad that are not present in the free play situation. SSRI-alone mothers seemed to be able to cope with infant negative affect in less demanding situations, however when additional demands were posed as in the structured play they were overwhelmed. For the SSRI+ mothers, even meager demands of the free play situation posed challenges. This raises the possibility that the mothers in the psychotropic exposed groups are perhaps experiencing difficulties in dyadic affect regulation related to infant negative affect. They may also be experiencing difficulties in repairing interactive errors (Gianino and Tronick, 1988; Tronick and Weinberg, 1997).

Maternal sensitivity was also significantly and positively related to infant negative affect in the SSRI+ group during both free and structured play. There was little variation between the correlations during the two different interaction sequences and we therefore speculate that the mothers in the SSRI+ group are overwhelmed by their infants' negative affect. By focusing exclusively on infant negative affect and perhaps becoming too intrusive, these mothers are less able to read the infant's cues and gain the needed information to respond appropriately and help their infant to co-regulate their mood.

In the SSRI+ group, there were significant correlations between negative infant affect and all maternal variables in both structured and free play. SSRI+ mothers whose infants were displaying higher levels of negative affect were themselves less positive, less sensitive, and more negative in their affect.

According to the priority hypothesis, affect regulation takes priority over other components of self-regulation such as for example attentional and social domains (Tice et al., 2001). Negative emotions therefore shift self-regulatory attempts from long-term goals to short-term feeling states as alleviation of emotional distress takes precedence. When the hypothesis is applied to this study, the behaviors of mothers in the SSRI-alone and SSRI+ group can be partially understood. These mothers may be more invested in regulating their own affect rather than regulating interactions with their infants in demanding play situations.

There was no significant association observed with SSRI+ mothers' variables toward infant sober mood during both structured and free play sequences. When infants express sober moods, mothers in the control or SSRI-alone groups are taking some measures to respond or repair errors; SSRI+ mothers however seem less burdened with infant sober mood. More negative infant affect expression is probably required in other to make SSRI+ mothers react.

\section{SELF-REGULATION}

Our data did not support the hypothesis that infants who are exposed to the psychotropics in utero and infants whose mothers have comorbid pathologies (anxiety and depression) are more at risk for impaired self-regulation capacities.

\section{SOCIAL BEHAVIOR}

The audience effect (where infants smile in response to presence of another) is not expected to be fully developed at age of 8 months, therefore infant expressions provide important information within the context of the mother-infant relationship. A mother's mirroring functions are an important aspect of this mutual regulation process and an emotional scaffolding experience for the infant (Papousek and Papousek, 1979). In the SSRI+ group, these mirroring functions as judged by affect expression of the infants may be considered to be different. Fonagy et al. (2002) explain disturbed reflective functions of the mother in being too uninvolved or too accurate can both be just as devastating for the infant. Fonagy explains this phenomenon in that, too much primary experience without modulation overwhelms the infant. This may be the case with the SSRI+ group.

Mothers from SSRI+ group reacted with negative physical contact in response to infants' aversion in the free and structured task situations. On PCERA, negative physical contact can range from awkward, abrupt and or insensitive handling to intense tickling and/or rough and tumble play to physical restraint, pinching, hitting. There were no safety or protection concerns raised during videotaping or detected during coding procedures on any of the tapes. Although control mothers also reacted negatively to infants' avoidance and resistance, they were adequately cueing on infant's other social behaviors, thus possibly correcting interactive errors. 
It is difficult to speculate why control and SSRI-alone groups' infants were similar whilst the SSRI+ group infants were reacting differently in their affect expression and social behavior patterns. Some plausible explanations include the clinical improvement of mood in SSRI-alone group mothers, unequal burden of maternal illness in the two experimental, possible neurodevelopmental stress associated with the combination of SSRIs and benzodiazepines, as well as variable impact of psychosocial factors.

\section{METHODOLOGICAL LIMITATIONS}

There are limitations to this study, which include study specific and general difficulties in conducting infant research away from a naturalistic setting; i.e., the constraint of free play whilst videotaping and also the anxiety of attempting an unfamiliar task (Martin et al., 2002). One study specific limitation is the small sample size that limits statistical power in multiple comparison adjustments. Another limitation is the absence of a third group of untreated non-psychotropic exposed depressed mother-infant dyads. An additional issue is the degree to which the findings may be taken as being representative of the diagnostic group under scrutiny. Clinicians who deal with depressed mothers know that it is almost impossible to obtain a truly monodiagnostic sample of peripartum depressed women due to the wide overlapping spectra of the two affective disorders, i.e., anxiety and depression. The limitations of measures used also deserve further discussion. For example, mother-child interaction in videotapes may not accurately depict the mutual regulation difficulties of the dyad that can be picked up on more sophisticated micro analytic facial expression coding system or longitudinal examination of relational patterns. Another limitation is the absence of HAM-D measures for control group at 8 months. In keeping with asymptomatic clinical status of control mothers both at 2 and 8 months, HAM-D was not repeated at 8 months as similar scores were anticipated. In order to correlate maternal mood with mutual regulation variables in all three groups, correlations between mutual regulation variables 8 months and HAM-D scores at 2 months were calculated for this group.

\section{CONCLUSION}

Despite the limitations, this study has raised clinically relevant issues. Infants from the SSRI-alone group shared many common characteristics with the controls, as compared to SSRI+ group of infants, regarding their affect expression patterns. However, these intra-group differences were not statistically significant in infants' self-regulation capacities. The SSRI-alone (maternal depression) and control mothers may have been cueing to

\section{REFERENCES}

Aitken, A. R., and Tork, I. (1988). Early development of serotonincontaining neurons and pathways as seen in wholemount preparations of the fetal rat brain. J. Comp. Neurol. 274, 32-47.

Bakker, M. K., Kolling, P., Van Den Berg, P. B., De Walle, H. E., and De Jong Van Den Berg, L. T. (2008). Increase in use of selective serotonin reuptake inhibitors in pregnancy during the last decade, a populationbased cohort study from the Netherlands. Br. J. Clin. Pharmacol. 65, 600-606.

Bayley, N. (1993). Bayley Scales of Infant Development. Second Edn. San Antonio: The Psychological Corportation.

Bernier, A., Carlson, S. M., and Whipple, N. (2010). From external regulation to self-regulation: early parenting precursors of young children's

infants' affective experiences differently from the SSRI+ group of mothers (maternal depression with comorbid anxiety disorder). The clinical implication of these findings is not entirely clear. There is evidence to indicate that comorbid pathology with maternal depression may be more problematic for motherinfant dyadic adjustment than the risk conferred by depression alone (Carter et al., 2001). These mothers usually require combinations of psychotropics. There is an urgent need to provide more supportive networking and insightful therapies such as cognitive therapies to improve the reflective functions of the mother by targeting mother-infant interactional patterns. Finally, the head circumferences of control and SSRI+ group infants were significantly larger than those of infants from the SSRIalone group (Nulman et al., 1997; Casper et al., 2003); this finding needs replication, along with robust neurodevelopmental data.

\section{CLINICAL IMPLICATIONS}

Clinicians who treat anxious and depressed pregnant women face several ethical and clinical dilemmas. Interventions offered during pregnancy have to respect mothers and their developing fetuses. The use of psychotropic medications in pregnancy is considered to treat moderate to severe maternal mental illness. Untreated maternal anxiety and depression also confer developmental and relational risks. This study presents clinically significant findings regarding affect expression in infants of mothers burdened with depression and anxiety who received psychotropic medications during pregnancy. In this study, the longitudinal examination of control infants and infants exposed to monotherapy (maternal depression without comorbid anxiety disorder) was similar in their patterns of self-regulation and affect expression. A different pattern was evident with infants who were exposed in utero to a combination of SSRIs and benzodiazepines (comorbid maternal depression and anxiety disorder) when compared to the healthy dyads. This finding needs to be replicated in studies with larger sample sizes. Nevertheless, serious clinical implications of the mixed burden of maternal anxiety and depression and other potential stressors such as in utero psychotropic medication exposure should be considered.

\section{ACKNOWLEDGMENTS}

This research was made possible with funds obtained from British Columbia's Medical Research Foundation. We would like to thank all the families who participated in this study and the Department of Reproductive Psychiatry; the Department of Developmental Pediatrics, and the Neonatal Laboratory staff.

executive functioning. Child Dev. 81, 326-339.

Buitelaar, J. K., Huizink, A. C., Mulder, E. J., De Medina, P. G., and Visser, G. H. (2003). Prenatal stress and cognitive development and temperament in infants. Neurobiol. Aging 24(Suppl. 1), S53-S60; discussion S67-S68.

Calkins, S. D., and Fox, N. A. (2002). Self-regulatory processes in early personality development: a multilevel approach to the study of childhood social withdrawal and aggression. Dev. Psychopathol. 14, 477-498.

Campbell, S. B., Brownell, C. A., Hungerford, A., Spieker, S. I., Mohan, R., and Blessing, J. S. (2004). The course of maternal depressive symptoms and maternal sensitivity as predictors of attachment security at 36 months. Dev. Psychopathol. 16, 231-252. 
Carter, A. S., Garrity-Rokous, F. E., Chazan-Cohen, R., Little, C., and Briggs-Gowan, M. J. (2001). Maternal depression and comorbidity: predicting early parenting, attachment security, and toddler socialemotional problems and competencies. J. Am. Acad. Child Adolesc. Psychiatry 40, 18-26.

Casper, R. C., Fleisher, B. E., LeeAncajas, J. C., Gilles, A., Gaylor, E., Debattista, A., and Hoyme, H. E. (2003). Follow-up of children of depressed mothers exposed or not exposed to antidepressant drugs during pregnancy. J. Pediatr. 142, 402-408.

Casper, R. C., Gilles, A. A., Fleisher, B. E., Baran, J., Enns, G., and Lazzeroni, L. C. (2011). Length of prenatal exposure to selective serotonin reuptake inhibitor (SSRI) antidepressants: effects on neonatal adaptation and psychomotor development. Psychopharmacology (Berl.) 217, 211-219.

Clark, R. (1985). The Parent-Child Early Relational Assessment. Madison: Department of Psychiatry, University of Wisconsin Medical School.

Clarke, A. S., and Schneider, M. L. (1997). Effects of prenatal stress on behavior in adolescent rhesus monkey. Ann. N. Y. Acad. Sci. 807, 490-491.

Cohen, L. S., Heller, V. L., and Rosenbaum, J. F. (1989). Treatment guidelines for psychotropic drug use in pregnancy. Psychosomatics 30, 25-33.

Davids, A., Holden, R. H., and Gray, G. B. (1963). Maternal anxiety during pregnancy and adequacy of mother and child adjustment eight months following childbirth. Child Dev. 34, 993-1002.

Deave, T., Heron, J., Evans, J., and Emond, A. (2008). The impact of maternal depression in pregnancy on early child development. BJOG 115, 1043-1051.

Einarson, A., Fatoye, B., Sarkar, M., Lavigne, S. V., Brochu, J., Chambers, C., Mastroiacovo, P., Addis, A., Matsui, D., Schuler, L., Einarson, T. R., and Koren, G. (2001). Pregnancy outcome following gestational exposure to venlafaxine: a multicenter prospective controlled study. Am. J. Psychiatry 158, 1728-1730.

Eisenberg, N., Guthrie, I. K., Fabes, R. A., Shepard, S., Losoya, S., Murphy, B. C., Jones, S., Poulin, R., and Reiser, M. (2000). Prediction of elementary school children's externalizing problem behaviors from attentional and behavioral regulation and negative emotionality. Child Dev. 71, 1367-1382.

Field, T. (1998). Early interventions for infants of depressed mothers. Pediatrics 102, 1305-1310.

Field, T. (2011). Prenatal depression effects on early development: a review. Infant Behav. Dev. 34, 1-14.

Fonagy, P., Gergely, G., Target, M., and Jurist, E. L. (2002). Affect Regulation, Mentalization, and the Development of the Self. New York: Other Press.

Gentile, S. (2005). SSRIs in pregnancy and lactation: emphasis on neurodevelopmental outcome. CNS Drugs 19, 623-633.

Gentile, S. (2010). Neurodevelopmental effects of prenatal exposure to psychotropic medications. Depress. Anxiety 27, 675-686.

Gentile, S., and Bellantuono, C. (2009). Selective serotonin reuptake inhibitor exposure during early pregnancy and the risk of fetal major malformations: focus on paroxetine. J. Clin. Psychiatry 70, 414-422.

Gianino, A., and Tronick, E. Z. (1988). "The mutual regulation model: the infant's self and interactive regulation and coping and defensive capacities," in Stress and Coping, eds T. Field, P. Mccabe, and N. Schneiderman (Hillside, NJ: Lawrence Erlbaum Associates), 47-68.

Goldstein, D. J., Sundell, K. L., and Corbin, L. A. (1997). Birth outcomes in pregnant women taking fluoxetine. N. Engl. J. Med. 336, 872-873; author reply 873 .

Guy, W. (1976). ECDEU Assessment Manual for Psychopharmacology. Rockville, MD: National Institute of Mental Health.

Hamilton, M. (1959). The assessment of anxiety states by rating. $\mathrm{Br}$. J. Med. Psychol. 32, 50-55.

Hamilton, M. (1960). A rating scale for depression. J. Neurol. Neurosurg. Psychiatr. 23, 56-62.

Hebebrand, J., Hofmann, D., Reichelt, R., Schnarr, S., Knapp, M., Propping, P., and Fodisch, H. J. (1988). Early ontogeny of the central benzodiazepine receptor in human embryos and fetuses. Life Sci. 43, 2127-2136.

Herlenius, E., and Lagercrantz, $\mathrm{H}$. (2001). Neurotransmitters and neuromodulators during early human development. Early Hum. Dev. 65, 21-37.

Huizink, A. C., and Buitelaar, J. K. (2000). Prenatal Stress and its Effect on Infant Development. Utrecht: Proefschrift Universiteit Utrecht.

Koren, G., and Nickel, C. (2011). Perpetuating fears: bias against the null hypothesis in fetal safety of drugs as expressed in scientific citations. J. Popul. Ther. Clin. Pharmacol. 18 e28-e32.

Le Strat, Y., Dubertret, C., and Le Foll, B. (2011). Prevalence and correlates of major depressive episode in pregnant and postpartum women in the United States. J. Affect. Disord. 135 128-138.

Marcus, S. M. (2009). Depression during pregnancy: rates, risks and consequences - Motherisk Update 2008. Can. J. Clin. Pharmacol. 16, e15-e22.

Martin, S. E., Clements, M. L., and Crnic, K. A. (2002). Maternal emotions during mother-toddler interaction: parenting in affective context. Parent. Sci. Pract. 2, 105-126.

Maughan, A., Cicchetti, D., Toth, S. L., and Rogosch, F. A. (2007). Earlyoccurring maternal depression and maternal negativity in predicting young children's emotion regulation and socioemotional difficulties. $J$. Abnorm. Child. Psychol.35, 685-703.

McElhatton, P. R. (1994). The effects of benzodiazepine use during pregnancy and lactation. Reprod. Toxicol. 8, 461-475.

Misri, S., Burgmann, A., and Kostaras, D. (2000). Are SSRIs safe for pregnant and breastfeeding women? Can. Fam. Physician 46, 626-628, 631-623.

Misri, S., Oberlander, T. F., Fairbrother, N., Carter, D., Ryan, D., Kuan, A. J., and Reebye, P. (2004). Relation between prenatal maternal mood and anxiety and neonatal health. Can. J. Psychiatry 49, 684-689.

Mulder, E. J., Ververs, F. F., De Heus, R., and Visser, G. H. (2011). Selective serotonin reuptake inhibitors affect neurobehavioral development in the human fetus. Neuropsychopharmacology 36, 1961-1971.

Nulman, I., Rovet, J., Stewart, D. E., Wolpin, J., Gardner, H. A., Theis, J. G., Kulin, N., and Koren, G. (1997). Neurodevelopment of children exposed in utero to antidepressant drugs. N. Engl. J. Med. 336 258-262.

Oberlander, T. F., Misri, S., Fitzgerald, C. E., Kostaras, X., Rurak, D., and Riggs, W. (2004). Pharmacologic factors associated with transient neonatal symptoms following prenatal psychotropic medication exposure. $J$ Clin. Psychiatry 65, 230-237.

Oberlander, T. F., Weinberg, J., Papsdorf, M., Grunau, R., Misri, S., and Devlin, A. M. (2008). Prenatal exposure to maternal depression, neonatal methylation of human glucocorticoid receptor gene $(\mathrm{NR} 3 \mathrm{C} 1)$ and infant cortisol stress responses. Epigenetics 3, 97-106.
O’Connor, T. G., Heron, J., Golding, J., Beveridge, M., and Glover, V. (2002). Maternal antenatal anxiety and children's behavioural/emotional problems at 4 years. Report from the Avon Longitudinal Study of Parents and Children. Br. J. Psychiatry 180 502-508.

Papousek, H., and Papousek, M. (1979). "Early ontogeny of human social interaction: its biological roots and social dimensions," in Human Ethnology: Claims and Limits of a New Discipline, eds M. Von Cranach, K. Foppa, W. Lepennies, and D. Ploog (Cambridge, MA: Cambridge University Press), 456-478.

Pastuszak, A., Schick-Boschetto, B., Zuber, C., Feldkamp, M., Pinelli, M., Sihn, S., Donnenfeld, A., Mccormack, M., Leen-Mitchell, M., Woodland, C., et al. (1993). Pregnancy outcome following first-trimester exposure to fluoxetine (Prozac). JAMA 269, 2246-2248.

Posner, M. I., and Rothbart, M. K. (2002). Developing mechanisms of self-regulation. Dev. Psychopathol. 12, 427-441.

Reebye, P. N., Morison, S. J., Panikkar, H., Misri, S., and Grunau, R. E. (2002). Affect expression in prenatally psychotropic exposed and nonexposed mother-infant dyads. Infant Ment. Health J. 23, 403-416.

Sackett, J. C., Weller, R. A., and Weller, E. B. (2009). Selective serotonin reuptake inhibitor use during pregnancy and possible neonatal complications. Curr. Psychiatry Rep. 11, 253-257.

Schneider, M. L. (1992). Prenatal stress exposure alters postnatal behavioral expression under conditions of novelty challenge in rhesus monkey infants. Dev. Psychobiol. 25, 529-540.

Schore, A. N. (1994). Affect Regulation and the Origin of the Self: The Neurobiology of Emotional Development. Hillside, NJ: Lawrence Erlbaum Associates.

Simon, G. E., Cunningham, M. L., and Davis, R. L. (2002). Outcomes of prenatal antidepressant exposure. Am. J. Psychiatry 159, 2055-2061.

Stern, D. (1995). The Motherhood Constellation: A Unified View of ParentInfant Psychotherapy. New York: Basic Books.

Taveras, E. M., Capra, A. M., Braveman, P. A., Jensvold, N. G., Escobar, G. J., and Lieu, T. A. (2003). Clinician support and psychosocial risk factors associated with breastfeeding discontinuation. Pediatrics 112, 108-115.

Tice, D. M., Bratslavsky, E., and Baumeister, R. F. (2001). Emotional 
distress regulation takes precedence over impulse control: if you feel bad, do it! J. Pers. Soc. Psychol. 80, 53-67.

Tronick, E. Z., and Weinberg, M. K. (1997). "Depressed mothers and their infants: failure to form dyadic states of consciousness," in Postpartum Depression and Child Development, eds L. Murray, and P. J. Cooper (New York: Guilford Press), 54-81.

Tuccori, M., Testi, A., Antonioli, L., Fornai, M., Montagnani, S., Ghisu, N., Colucci, R., Corona, T., Blandizzi, C., and Del Tacca, M. (2009). Safety concerns associated with the use of serotonin reuptake inhibitors and other serotonergic/noradrenergic antidepressants during pregnancy: a review. Clin. Ther. 31( $\mathrm{Pt} 1)$, 1426-1453.

Udechuku, A., Nguyen, T., Hill, R., and Szego, K. (2010). Antidepressants in pregnancy: a systematic review. Aust. N. Z. J. Psychiatry 44, 978-996.

Van den Bergh, B. R., and Marcoen, A. (2004). High antenatal maternal anxiety is related to ADHD symptoms, externalizing problems, and anxiety in 8and 9-year-olds. Child Dev. 75, 1085-1097.

Way, C. M. (2007). Safety of newer antidepressants in pregnancy. Pharmacotherapy 27, 546-552.

Weinberg, M. K., Beeghly, M., Olson, K. L., and Tronick, E. (2008). Effects of maternal depression and panic disorder on motherinfant interactive behavior in the face-to-face still-face paradigm. Infant Ment. Health J. 29, 472-491.

Welch, E., Fees, B., and Murray, A. D. (2003). Parent-toddler play interaction and its relation to the home environment. Undergrad. Res. J. Human Sci. 2. Available at: http://www.kon.org/urc/welch. html

Conflict of Interest Statement: The authors declare that the research was conducted in the absence of any commercial or financial relationships that could be construed as a potential conflict of interest.
Received: 28 October 2011; accepted: 03 February 2012; published online: $28 \mathrm{Feb}$ ruary 2012.

Citation: Reebye PN, Ng TWC, Misri $S$ and Stikarovska I (2012) Affect expression and self-regulation capacities of infants exposed in utero to psychotropics. Front. Psychiatry 3:11. doi: 10.3389/fpsyt.2012.00011

This article was submitted to Frontiers in Child and Neurodevelopmental Psychiatry, a specialty of Frontiers in Psychiatry. Copyright (c) 2012 Reebye, Ng, Misri and Stikarovska. This is an open-access article distributed under the terms of the Creative Commons Attribution Non Commercial License, which permits noncommercial use, distribution, and reproduction in other forums, provided the original authors and source are credited. 